\title{
Standard precision and aggressive financial reporting: the influence of incentive horizon
}

\author{
Kara E. Hunter, Jacob M. Rose, Atm Tariquzzaman \& Jay C. Thibodeau
}

To cite this article: Kara E. Hunter, Jacob M. Rose, Atm Tariquzzaman \& Jay C. Thibodeau (2021): Standard precision and aggressive financial reporting: the influence of incentive horizon, Accounting and Business Research, DOI: 10.1080/00014788.2021.1952059

To link to this article: https://doi.org/10.1080/00014788.2021.1952059

曲 Published online: 27 Aug 2021.

Submit your article to this journal $₫$

Q View related articles $\sqsubset$

View Crossmark data 


\title{
Standard precision and aggressive financial reporting: the influence of incentive horizon
}

\author{
KARA E. HUNTER ${ }^{\mathrm{a}}$, JACOB M. ROSE ${ }^{\mathrm{bc} *}$, ATM TARIQUZZAMAN ${ }^{\mathrm{d}}$ and \\ JAY C. THIBODEAU ${ }^{\mathrm{e}}$
}

${ }^{a}$ School of Business, Fairfield University, Fairfield, CT, USA; ${ }^{b}$ School of Accounting, Finance and Economics, University of Waikato, Hamilton, New Zealand; ${ }^{c}$ Department of Accounting, Monash University, Clayton, Australia; ${ }^{d}$ School of Accounting and Commercial Law, Victoria University of Wellington, Wellington, New Zealand; ${ }^{e}$ Department of Accountancy, Bentley University, Waltham, MA, USA

\begin{abstract}
The extant literature on precision in accounting standards suggests that financial statement preparers are less likely to make aggressive financial reporting decisions under less precise, principles-based accounting standards as compared to under more precise, rules-based accounting standards. We extend this line of research by examining how the incentive horizon of financial statement preparers influences earnings management behaviour. Consistent with prior literature, we find evidence that more precise standards lead to more income-increasing earnings management behaviour than do less precise standards when the incentive horizon is short-term in nature. However, when the incentive horizon is longterm, more precise standards are associated with financial reporting decisions that reduce current income relative to less precise standards. Importantly, the findings demonstrate that the effects of standard precision are changed by the incentive time horizon, and the effects of standard precision on financial decision makers cannot be fully understood when precision is studied without considering the timing of management incentive structures.
\end{abstract}

Keywords: incentive time horizon; principles-based standards; rules-based standards; standard precision

JEL Classification: M41; M48; G38

\section{Introduction}

Proponents of rules-based standards suggest that greater standard precision improves comparability between companies by providing bright-line tests and thresholds that reduce the need for judgment in the application of standards (Schipper 2003, Nelson 2003, Shortridge and Myring 2004). Reductions in the amount of judgment needed to apply standards are expected to decrease opportunities to manage earnings (Wüstemann and Wüstemann 2010). However,

\footnotetext{
*Corresponding author. Email: jake.rose@waikato.ac.nz Paper accepted by Christoph Pelger.
} 
existing empirical evidence does not support this point of view. Rather, the prior literature suggests that managers use the specificity of rules in order to structure transactions in a manner that achieves a specific accounting outcome that is consistent with their personal incentives rather than the true economic substance of the transaction (Imhoff and Thomas 1988). Financial statement preparers are also more inclined to engage in aggressive financial reporting under more precise standards relative to less precise standards (Agoglia et al. 2011).

While empirical research supports the view that less precise standards can increase reporting quality and reduce aggressive reporting, the prior research has consistently examined the decisions of financial statement preparers who had short-term management incentive structures. The purpose of this study is to investigate whether the incentive time horizon (i.e. whether incentives emphasise short-term or long-term firm goals) will moderate the relationship between standard precision and earnings management behaviour. If the effects of standard precision on financial statement preparers' decisions change with the incentive time horizon, then debates about the costs and benefits of standard precision are currently being informed by an incomplete story.

The structure of incentives can encourage a focus on short-term profitability or long-term performance, and as a result, structuring incentives for employees is a critical decision for top management and for remuneration committees when setting the pay structures for executive management. Indeed, for compensation to properly motivate decision makers to work towards achieving firm strategic objectives, the incentive structure should align with the strategic focus of the firm (Schuler and MacMillan 1984, Balkin and Gomez-Mejia 1990). For example, short-term incentives (such as unrestricted stock grants or stock options) may incentivise individuals to give priority to short-term profitability and encourage aggressive financial reporting, potentially at the expense of long-term growth (Dechow and Sloan 1991, Narayanan 1996, Antia et al. 2010). In contrast, restricted forms of compensation (such as stock grants and options with vesting and/or holding requirements) may extend the incentive time horizon of management, reduce myopic behaviour (Chava and Purnanandam 2010, Bebchuk and Fried 2010), and potentially discourage income-increasing earnings management behaviour (Johnson et al. 2009). Consistent with prior literature, we expect that a firm's choice of management incentive structure will influence financial statement preparers' likelihood to engage in earnings management behaviour, and that these effects will interact with standard precision.

In this study, we examine the effect of incentive horizon and standard precision on financial statement preparers' reporting decisions. Specifically, we extend the Agoglia et al. (2011) study by investigating the effects of incentive time horizon on a financial statement preparer's financial reporting decisions. We propose that when the incentive time horizon is short-term, financial statement preparers applying less precise standards will be less likely to engage in incomeincreasing earnings management behaviour. However, when the incentive time horizon is long-term, the effects of standard precision will change because these incentives signal top managements' preference for long-term performance, rather than short-term performance, thereby shifting preparers' focus from short term regulatory oversight (e.g. avoiding the potential sanctions related to decisions from regulators) to long-term firm performance goals. We expect this will result in an increase in income-increasing earnings management behaviour when standards are less precise.

To accomplish our objectives, we conduct a $2 \times 2$ between-participants experiment with 135 experienced financial statement preparers, over half of whom are Chief Financial Officers, from both the United States and Bangladesh. ${ }^{1}$ Participants complete a lease classification case where

\footnotetext{
${ }^{1}$ It was important to include participants from countries that operate under different standard regimes to ensure that results are not driven by familiarity with a particular set of standards. We control for the potential
} 
we manipulate standard precision (more precise or less precise) and the time horizon of incentives (short-term or long-term). We find a significant interaction between standard precision and time horizon of incentives on a financial statement preparer's reporting decisions. More specifically, our results show that when the time horizon of incentives focuses financial statement preparers on long-term firm performance, a more precise, rules-based standard regime results in less income-increasing earnings management behaviour than less precise standards. These effects are opposite to those found when the incentive structures stress short-term earnings targets. Indeed, our highly experienced participants change their response relative to standard precision in the face of different incentive time horizons.

The results of this study have several important implications. We provide evidence that the time horizon of decisions created by top management's incentive structure influences the relationship between accounting standard precision and the income-increasing earnings management behaviour that has been observed in prior research. This suggests that the effects of standard precision on earnings management behaviour cannot be fully understood without first considering the time horizon of the incentive structure. The finding is particularly important given the increasing use of incentive structures that include components designed to promote greater emphasis on longterm performance, such as holding requirements for stock-based compensation (Lovett et al. 2021). Our results suggest that when the incentive structure emphasises long-term performance, principles-based standards are associated with increased earnings management behaviour, which is contrary to existing findings of studies that have previously not considered incentive structures.

The remainder of this study is organised as follows. Section II provides background information and develops our hypothesis. Sections III describes the experiment used to test our hypothesis. Section IV provides our experimental results, and Section V discusses our conclusions, implications, limitations of our research, and suggestions for future research.

\section{Background and hypothesis development}

\subsection{Standard precision}

The discourse related to accounting standard precision often regards IFRS as a principles-based standards system relative to U.S. GAAP, which is often regarded as a rules-based standards system. In reality, however, the characterisation of a standard system as either principlesbased or rules-based is both challenging and problematic. ${ }^{2}$ Consider that the standards of both U.S. GAAP and IFRS are both written to operationalise conceptual frameworks, which suggests that at some level, both standard systems could be regarded as principles-based (Schipper 2003, Schipper 2005, Nelson 2003, Nobes 2005). Yet the resulting standards quite often do vary in the extent to which rules are incorporated. As a result, those standards that incorporate fewer rules (such as bright-line tests and thresholds) must rely more on the underlying principle and are considered to be more principles-based (Nelson 2003). In contrast, those standards that are able to incorporate rules to a greater extent are generally regarded as more rules-based (Alexander 1999, Nelson 2003, Nobes 2005, Ball 2016).

Rules-based accounting standards provide more precise guidance for preparers, including examples, subsequent precedents, and implementation guidance (Nelson 2003). Advocates for

effects of cultural difference by including a country indicator variable in our statistical models, and all results are insensitive to a participant's country.

${ }^{2}$ Examples of both rules-based and principles-based standards exist within a single standard system and may co-exist within a single standard. For example, while IFRS is generally regarded as more principles-based, both IFRS 15 -Revenue from Contracts with Customers and IFRS 16-Leases contain a number of specific rules. 
rules-based standards maintain that the precise guidance offered by rules-based standards provides a common knowledge base and set of assumptions to be used in reporting decisions (Schipper 2003, Shortridge and Myring 2004). The precise criteria of rules-based standards are intended to remove the extent to which preparer judgment is involved in the classification process and improve comparability between firms (Schipper 2003, Nelson 2003, Shortridge and Myring 2004, Schipper 2005). However, it is also possible that the bright-line rules and thresholds encourage opportunistic transaction structuring designed to circumvent the true spirit of standards. ${ }^{3}$ Further, dissimilar transactions that are forced into the same accounting treatment may, in fact, threaten comparability across organisations (McCarthy and McCarthy 2014).

Principles-based standards allow transactions to be recorded in a manner that best represents the underlying economic substance of the transaction (Shortridge and Myring 2004, Ball 2016). ${ }^{4}$ Further, when applied properly, principles-based standards 'better support the FASB's stated mission of 'improving the usefulness and relevance of financial reporting by focusing on the primary characteristics of relevance and reliability.' (AAA FASC 2003, 74). A perceived weakness of principles-based standards is that financial statement preparers may not apply such standards consistently or appropriately, as there is a greater degree of interpretation and judgment involved in the application of the standard (McCarthy and McCarthy 2014). Additionally, incentives may be present that influence the behaviour of financial statement preparers (Nelson 2003, Wüstemann and Wüstemann 2010) because the opportunity to select preferential accounting treatments may be greater under principles-based standards as compared to rules-based standards (McCarthy and McCarthy 2014).

In that spirit, several studies relating to accounting standard precision examine factors that influence reporting decisions made by financial statement preparers. Peytcheva (2021) examines the relationship between standard precision and incentive-consistent reporting decisions while varying the ambiguity of evidence using a centuries-old psychological task (Jastrow $1899,1900)$. The study finds that when evidence is less ambiguous there is no difference in incentive-consistent reporting under either standard type, yet when the evidence is more ambiguous, principles-based standards better constrain incentive-consistent reporting. Psaros and Trotman (2004) examine the effect of incentives on a manager's decision to report aggressively, finding that marginally fewer participants make incentive-consistent reporting decisions when presented with principles-based standards. Agoglia et al. (2011) use a case in which participants are asked to determine the appropriate classification of a lease. They find that participants applying a principles-based standard are significantly less likely to report aggressively than those applying a rules-based standard. Taken together, these studies suggest that principles-based standards better constrain aggressive financial reporting as compared to rules-based standards.

\footnotetext{
$\overline{{ }^{3} \text { For example, Imhoff and Thomas (1988) document a significant decline in capital leases and a correspond- }}$ ing increase in operating leases by companies that were previously capital-lease intensive following the release of Financial Accounting Standards Board (FASB)'s Statement of Financial Accounting Standard (SFAS) No. 13 Accounting for Leases. This standard required capital leases to be treated as assets and debt, which moved the treatment of such transactions from the footnotes to the balance sheet.

${ }^{4}$ The term 'economic substance of the transaction' is used frequently in the literature on standard precision but is rarely defined. This term borrows from tax law, where a transaction's economic substance is measured by the change in firm financial position (other than tax effects) due to a specific transaction (Schreiber 2014).
} 


\subsection{Financial incentive structure}

Agency problems are conflicts of interest that exist in a relationship when one party is expected to act in another party's best interest (Jensen and Meckling 1976). Within financial accounting, the agency problem is often presented as a conflict of interest between company management and the shareholders of the firm. Managerial ownership is viewed as one potential solution to the long-standing agency problem. Specifically, if members of management have an ownership stake in the company, their interests align more closely with those of investors (Jensen and Meckling 1976, Morck et al. 1988). However, as the proportion of management's wealth tied to company performance via stock-based compensation increased considerably in the 1990s, stock-based compensation also shouldered the blame for many high-profile accounting frauds. That is, stock-based compensation can provide incentives to improve short-term financial results through aggressive and potentially fraudulent financial reporting (Bebchuck and Fried 2003). This view is supported by studies that find that stock-based compensation is positively associated with management's likelihood to engage in earnings management behaviour (Cheng and Warfield 2005, Bergstresser and Philippon 2006).

Cheng and Warfield (2005) investigate the relationship between management equity incentives and earnings management. They find that managers with high equity incentives are more likely to report earnings that just meet or beat analysts' forecasts and are less likely to report negative earnings surprises. They also find that when management has consistently high equity incentives from stock-based compensation, management is less likely to report large positive earnings surprises. Chava and Purnanandam (2010) similarly demonstrate that executives choose financial policies based on risk-seeking incentives provided by stock-based compensation. Taken together, these findings suggest that stock-based compensation provides an incentive for management to act in a self-interested manner.

The findings that stock-based compensation can encourage self-interested behaviour often involve management short-termism. Marginson and McAuley (2008) define management short-termism as a preference for actions in the near term that have detrimental consequences for the long-term. Specifically, managers may prioritise their own financial interests by focusing on short-term results at the expense of long-term growth and profitability that may be more optimal for the firm and shareholders (Dechow and Sloan 1991, Narayanan 1996, Antia et al. 2010). In fact, Graham et al. (2005) find that seventy-eight percent of managers admit to sacrificing long-term value in order to smooth current earnings. To address the problem of management short-termism, Bebchuck and Fried (2010) propose a series of restrictions on stock-based compensation, such as vesting restrictions and unwinding limitations that, if adopted, would extend the time horizon of management incentives.

Johnson et al. (2009) examine the relationship between the type of equity incentive and the occurrence of corporate fraud. They find that executives of fraud firms have a greater percentage of compensation in the form of unrestricted stockholdings relative to executives at non-fraud firms and that unrestricted stockholdings are the largest incentive source relative to other forms of compensation. In a sense, unrestricted stockholdings can shorten the incentive time horizon of management. For example, Gopalan et al. (2014) find that shorter CEO pay duration (based on the vesting schedule of restricted stock grants and options) is associated with greater incentive to manipulate short-term performance, whereas longer CEO pay duration is associated with a lesser extent of income-increasing accruals. These findings are attributable to the incentive time horizon of the $\mathrm{CEO}$, as pay duration represents a financial incentive that affects the incentive time horizon of management.

Taken together, these studies indicate that stock-based compensation that lacks restrictions on the sale of stock grants or exercise of options encourages management short-termism by 
providing a financial incentive based on short-term performance. This behaviour is often inconsistent with the long-term interests of the company or its shareholders. However, vesting periods and stock holding requirements can be effective for reducing management short-termism by extending the incentive time horizon for management.

\subsection{Hypothesis development}

Agoglia et al. (2011) employ a decision case that provides only short-term incentives for financial preparers to engage in earnings management. Therefore, we expect to replicate their findings in an experimental condition that involves a short-term incentive horizon (i.e. when there are no holding requirements for stock-based compensation). Consistent with the prior research, we expect that when financial statement preparers are focused on short-term goals, the preparers will be more likely to manage current-year earnings when applying more precise accounting standards than financial statement preparers applying less precise accounting standards.

Agoglia et al. (2011) construct the argument that less precise standards will result in less earnings management than more precise standards based upon theories of justification. In essence, aggressive accounting choices are expected to be more difficult to justify to auditors and regulators when standards are less precise. Maines (2007) indicates that the bright-line rules in more precise standards make it easier for firms to justify earnings management, as long as these bright lines are not crossed. Further, Nelson et al. (2002) state that regulators are more likely to second-guess discretionary accounting choices, and preparers will be more concerned about their ability to justify accounting choices to regulators when standards are less precise, relative to more precise (Dichev et al. 2013). The results of Agoglia et al. (2011) and their debriefing analyses support the proposition that preparers are concerned about their ability to justify accounting choices to regulators when standards are less precise and incentives favour short-term performance goals.

We propose that justification concerns will shift away from regulatory oversight when the time horizon of earnings management decisions changes from short-term to long-term. The direction of earnings management (income-increasing or income-decreasing) is known to be dependent on the incentives of the preparers (Barth et al. 1999, DeFond and Jiambalvo 1993). When executives' incentive structures reward long-term performance, the executives will be focused more on maximising long-term firm value, rather than short-term profitability. In this environment, preparers will be concerned about their ability to justify to executives any decisions that sacrifice long-term value for short-term gain, and focus will move away from justification of current-year earnings (Brink et al. 2020). In the case of leases, preparers will become more concerned about avoiding long-term liabilities on the balance sheet and less concerned about meeting current-year earnings targets when the incentive horizon gets longer. In the face of this long-term view of the reporting decision, preparers will be less focused on auditor and regulatory scrutiny of the current-year effects of their decisions. This decreased concern about current oversight, coupled with increased concern about presenting the best financial statements for long-term success, will provide more freedom to preparers to take advantage of the flexibility of less precise standards to avoid capitalising leases.

At the same time, concerns about justifying decisions to regulators or auditors should decline significantly when incentives favour long-term performance because preparers no longer face pressures to increase short-term profitability. Consider that auditors and regulators are typically more concerned with earnings management that is intended to boost short-term profitability, relative to earnings management activities that are long-term (Gigler et al. 2014, Francis and Krishnan 1999). Indeed, both ISA No. 240 and SAS No. 99 explicitly alert auditors to be aware of excessive pressure on management to meet short-term analyst expectations and/or press releases 
when assessing the risk of fraud (IFAC 2009, AICPA 2002). When preparers have fewer concerns about justifying accounting choices to auditors and regulators, they should perceive increased freedom to use the flexibility of less precise standards to pursue desired financial outcomes.

Taken together, the shifts in concerns to pleasing superiors by pursuing long-term performance goals, decreased perceptions of the need to justify decisions to regulators, and the flexibility inherent in less precise rules all suggest that the effects of standard precision will change when the incentive horizon is long-term, relative to short-term. More specifically, we expect that the tendency to engage in earnings management behaviour will increase more for preparers using less precise standards, relative to more precise standards, when the incentive horizon changes from short-term to long-term. This expectation results from two factors. First, prior research finds that less precise standards result in less income-increasing earnings management behaviour than more precise standards when the incentive horizon is short-term. Therefore, given that earnings management is lower for less precise standards in a short-term incentive horizon, lengthening the incentive horizon has the capacity to reduce earnings management more for more precise standards, relative to less precise standards. Second, preparers facing long-term incentive horizons, relative to short-term horizons, will have decreased concerns about short-term oversight because their decisions will be driven by a focus on long-term firm goals, rather than shortterm earnings targets. Decreased concerns about immediate needs to justify decisions to regulators will provide more perceived freedom to take advantage of the flexibility inherent in less precise standards.

Hypothesis: When the incentive horizon changes from short-term to long-term, earnings management behaviour will increase more for less precise standards, relative to more precise standards.

\section{Research method}

\subsection{Participants and design}

Participants in the study are $135^{5}$ experienced financial statement preparers consisting of chief financial or accounting officers, controllers, heads of finance, and other senior accounting positions $^{6}$ from both the United States and Bangladesh. Fifty-nine participants are from the United States, while seventy-six are from Bangladesh. It was important to have participants from two different standard regimes, one with experience under U.S. GAAP and one with experience under Bangladesh Accounting Standards ${ }^{7}$, to reduce the likelihood that our results are driven by familiarity with a particular standard regime. ${ }^{8}$ Different countries also have different

\footnotetext{
${ }^{5}$ The original participant pool contained 146 financial statement preparers. As an attention check, participants were asked to identify both the accounting standard and the incentive structure that were presented in the case facts. Ninety-two percent of the participants were able to do so. Eleven participants who were unable to do so were removed from further analysis.

${ }^{6}$ The survey asked the participants to indicate their current positions in an open-ended format. Thirty-five responses were coded as heads of finance, which included the following: Director of Finance, Head of Accounting, Head of Finance, VP of Finance or Accounting, Senior VP of Finance or Accounting, Executive VP of Finance or Accounting.

${ }^{7}$ With the exception of IFRS 9 (which is presently being considered for adoption in Bangladesh), all Bangladesh Accounting Standards (BAS) have adopted all International Accounting Standards and International Financial Reporting Standards as of 2015.

${ }^{8}$ Using participants from two different countries introduces a number of considerations, including cultural differences between the two countries, institutional setting, strength of the regulatory regime, etc. To
} 
approaches to implementing and designing accounting regulations (Nobes 2006, Leuz 2010). Thus, taken together, the inclusion of participants from different countries allows for more robust tests of our hypothesis. Importantly, participants from both countries were randomly distributed across all experimental conditions. The participants had an average of 18 years of professional work experience, which was important given that our experiment requires participants to make a decision that would typically be made by experienced financial statement preparers. ${ }^{9}$

To test our hypothesis, we conduct an experiment that asks participants to assume the role of the financial statement preparer for a fictitious company in order to make a lease classification decision, partially replicating the Agoglia et al. (2011) study. ${ }^{10}$ Within the experiment, we manipulate our constructs of interest: STANDARD_PRECISION and INCENTIVE_HORIZON. ${ }^{11}$

The variable STANDARD_PRECISION is manipulated at two levels: more precise and less precise accounting standard. Participants in the more precise standard condition are provided with rules-based lease capitalisation criteria from ASC 840 Leases (i.e. a lease must be classified as a capital lease if the lease term is equal to 75 percent or more of the expected economic useful life of the asset). Participants in the less precise standard condition are provided with principlesbased lease capitalisation criteria from IAS 17 - Accounting for Leases (i.e. a lease must be classified as a capital lease if the lease term is for the major part of the expected economic useful life of the asset). The independent variable STANDARD_PRECISION is an indicator variable where zero represents the less precise treatment condition and one represents the more precise treatment condition.

It should be noted that the lease classification guidance provided to participants is from prior leasing standards, which were superseded after we administered the experiment. The FASB and IASB issued revised standards for accounting for leases (FASB issued ASC 842 on 25 February 2016 to replace ASC 840 and IASB issued IFRS 16 on 13 January 2016 to replace IAS 17). The new leasing standards are presently in effect. The fact that our experiment is based on a previous standard does not limit its generalizability for three main reasons. First, the standards were current at the time of the experiment. Second, our study is a partial replication and extension of the Agoglia et al. (2011) study, which is commonly cited as evidence that more precise standards lead to more earnings management. In order to replicate and extend this study, it is important to employ the same lease task such that the results are comparable. Third, the objective of this study is to examine the construct of standard precision rather than the impact of any particular accounting or lease standard. To ensure that our results are driven by the precision of accounting standard rather than any other variations in the case context, choosing guidance with as few differences as possible is essential. Given that there are more substantial differences between ASC 842 and IFRS 16, this would have potentially been problematic. Further, the construct of standard precision remains important and relevant, given that there remain standards that

address these issues, we included a country control variable in our analysis. None of our results are affected by the participants' countries of origin.

${ }^{9}$ With respect to the demographics of our participants (e.g., gender, number of years work experience) there were no significant differences between conditions and, when included in our analyses, the demographic variables were neither significant nor altered the conclusions that we draw in the study.

${ }^{10}$ This study received proper approval from an institutional review board prior to data collection.

${ }^{11}$ We also manipulated the psychological construct of future self-continuity for the financial statement preparers using a prime developed by Hershfield et al. (2012) as a second method of lengthening participants' incentive horizon. We anticipated a potential interactive effect of future-self continuity and standard precision on a financial statement preparer's decision to report aggressively. Preliminary analyses revealed there is no significant main or interactive effects of self-continuity, and the self-continuity measure is not considered further and collapsed within our analyses. 
differ in precision between the two different standard systems (e.g. ASC 810 and IFRS $10^{12}$ ) and within a standard system. ${ }^{13}$

The independent variable, INCENTIVE_HORIZON is manipulated at two levels: short-term and long-term. Participants in the short-term condition are told that a significant portion of management's compensation is paid in stock that can be sold at any time. In the long-term condition, participants are told that a significant portion of management's compensation is paid in stock that cannot be sold for five years or more. The independent variable INCENTIVE_HORIZON is an indicator variable where zero represents the short-term treatment condition and one represents the long-term treatment condition.

\subsection{Procedures}

The first page of the instrument collects demographic information about the participants. Next, participants are asked to assume the role of controller for a fictitious company. Participants receive background information about the company's financial health, indicating that the company is just shy of reaching its consensus analyst forecasted earnings for the year. All participants are told that company executives' bonuses and a significant portion of their salaries are paid in stock. Each participant then receives either the short-term or long-term INCENTIVE_HORIZON manipulation.

The instrument provides information about a lease classification issue that the financial statement preparer is facing. The experimental manipulation (STANDARD_PRECISION) includes either rules-based or principles-based lease classification criteria. Each participant is told that, for the decision at hand, they are to assume the only relevant criterion is the ratio of the lease term to the expected economic useful life of the leased asset. Participants are also provided with the following definitions, which are consistent with both ASC 840 and IAS 17:

'Lease term' is defined as the fixed non-cancelable term of the lease plus all periods covered by bargain renewal options.

'Bargain renewal options' allow the lessee to renew the lease for a rental sufficiently lower than the fair rental of the property such that exercise of the option appears, at the inception of the lease, to be reasonably assured.

The case facts state that the lease has a non-cancellable lease term of seven years, with the option to renew the lease for an additional year. The participant must first judge whether the rate for the additional year represents a bargain renewal option to determine if the additional year should be included in the lease term, and then judge whether the lease meets the criteria for capitalisation provided by the lease standard.

Participants receive a summary of the financial effects of each of the two accounting treatments. The summary demonstrates that the capitalisation of the lease provides less favourable financial results, whereas classifying the lease as an operating lease will increase projected earnings to

\footnotetext{
${ }^{12}$ ASC $810-10$ - Consolidation uses a threshold of 50 percent to determine control of an entity, whereas IFRS 10 - Consolidated Financial Statements uses principles-based terminology referencing the effective power of the parent company.

${ }^{13}$ Folsom, Hribar, Mergenthaler and Peterson (2016) analyse U.S. accounting standards to determine the extent to which each standard includes principles. They find that U.S. accounting standards vary in precision from heavily rules-based (e.g. ASC 815 - Derivatives, ASC 715 - Compensation - Retirement Benefits, and ASC 410 - Asset Retirement and Environmental Obligations) to largely principles-based (e.g. ASC 330 - Inventory and ASC 606 - Revenues from Contracts with Customers).
} 
meet the consensus analyst forecast. Thus, management has a short-term incentive to record the lease as an operating lease.

Participants then assess the likelihood that they would classify this lease as an operating lease or a capital lease on a ten-point scale where one represents 'Definitely classify as an operating lease' and ten represents 'Definitely classify as a capital lease.' There is no neutral mid-point because in practice preparers are required to make a decision about lease classification, and they cannot decide that they are neutral or are not going to make a decision. A scale with no neutral midpoint, therefore, has greater external validity than a scale with a neutral midpoint. Further, the inclusion of a neutral midpoint can complicate the interpretation of results and can hinder the reliability of scales (Raaijmakers et al. 2000, Worcester and Burns 1975, Kulas et al. 2008). The participant's lease classification decision is reverse coded for ease of interpretation. The dependent variable is EARNINGS_MANAGEMENT, and higher values are indicative of more earnings management. After responding to the dependent measure, participants respond to attention check and debriefing questions. ${ }^{14}$

\section{Results}

\subsection{Hypothesis tests}

The hypothesis is tested using a $2 \times 2$ ANOVA, and results are reported in Table 1 , Panel B. To test our hypothesis, we examine the interaction between STANDARD_PRECISION and INCENTI$V E \_H O R I Z O N$. The interaction is statistically significant $(p=0.026)$ and presented graphically in Figure 1.

The significant interaction reveals that the effects of STANDARD_PRECISION vary across the levels of INCENTIVE_HORIZON. To test whether there is a change in tendency to manage earnings, we conduct simple effects tests. The first test examines the lease decision when standards are more precise, and the incentive horizon is either short-term versus long-term. This difference is not statistically significant $(p=0.336)$. Thus, earnings management behaviour does not appear to change significantly for preparers using more precise standards when the incentive horizon changes from short-term to long-term. However, results are different for less precise standards. When standards are less precise, participants are less likely to manage earnings when the horizon is short-term (mean = 4.07) than when the horizon is long-term (mean $=5.91$ ). This difference is statistically significant $(p=0.014)$. Thus, preparers using less precise standards were more likely to manage earnings and classify the lease as operating when the incentive horizon was long-term, relative to short-term.

As an additional test of the hypothesis, we conduct a planned contrast test that compares the signed change in the lease decision when the incentive horizon changes from short-term to longterm for the less precise standards (mean change $=1.84$ ), relative to the same change for more precise standards (mean change $=-0.79)$. The contrast is statistically significant $(p=0.013)$,

\footnotetext{
${ }^{14}$ The instrument also contained information about the Research \& Development budget of the firm. This portion of the instrument was designed to detect any potential for preparers to switch between real and accruals-based earnings management under our experimental conditions. Detailed analyses revealed no evidence of switching between forms of earnings management, and there were no statistically significant effects for the alternative dependent variable that captured attempts at real earnings management. Therefore, these results are not tabulated. On average, participants in all treatment conditions cut approximately $\$ 1$ million from $R \& D$, indicating that participants used $R \& D$ to reach earnings targets, and then they employed the lease classification decision to reach CEO bonus targets.
} 


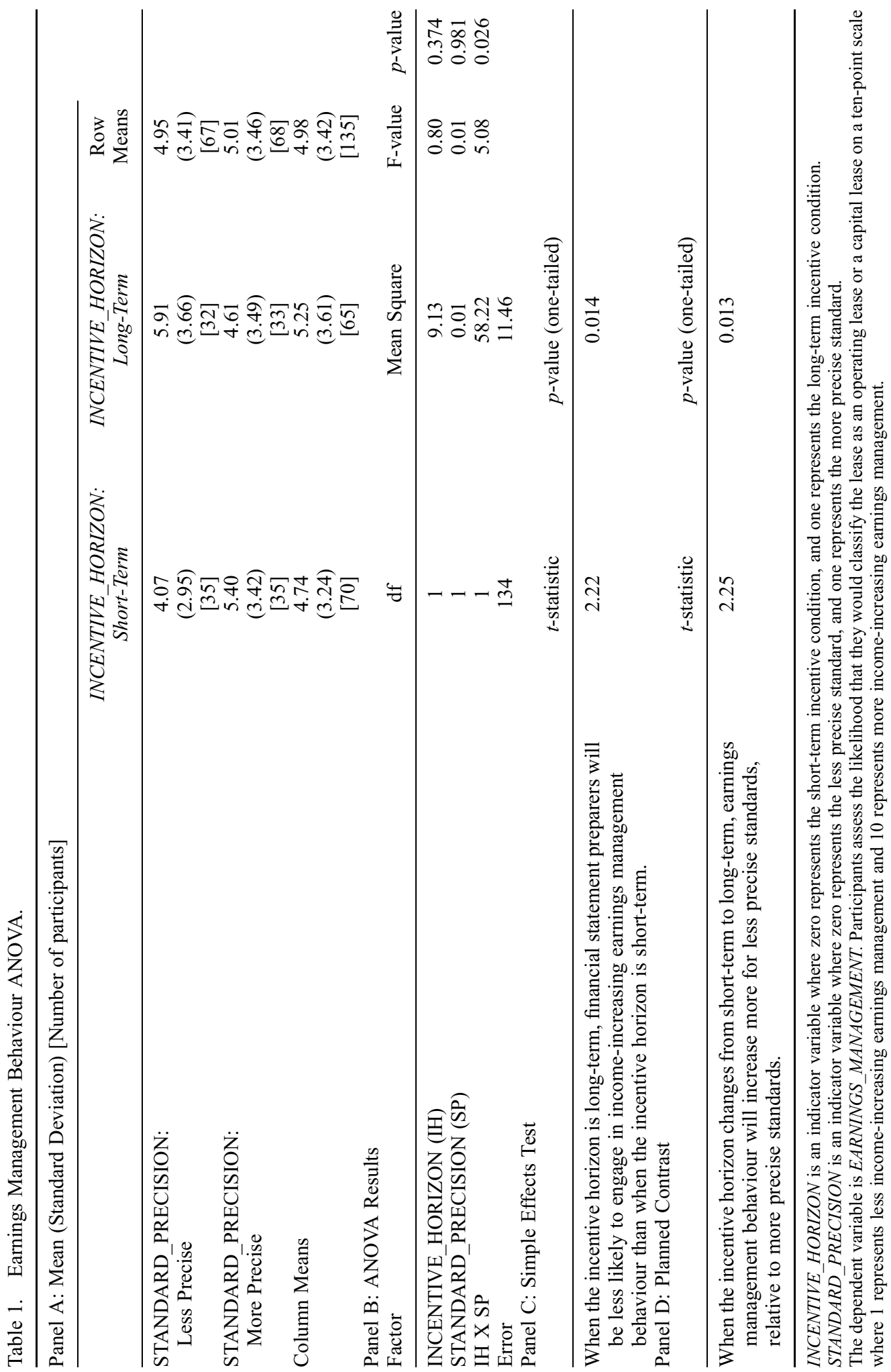




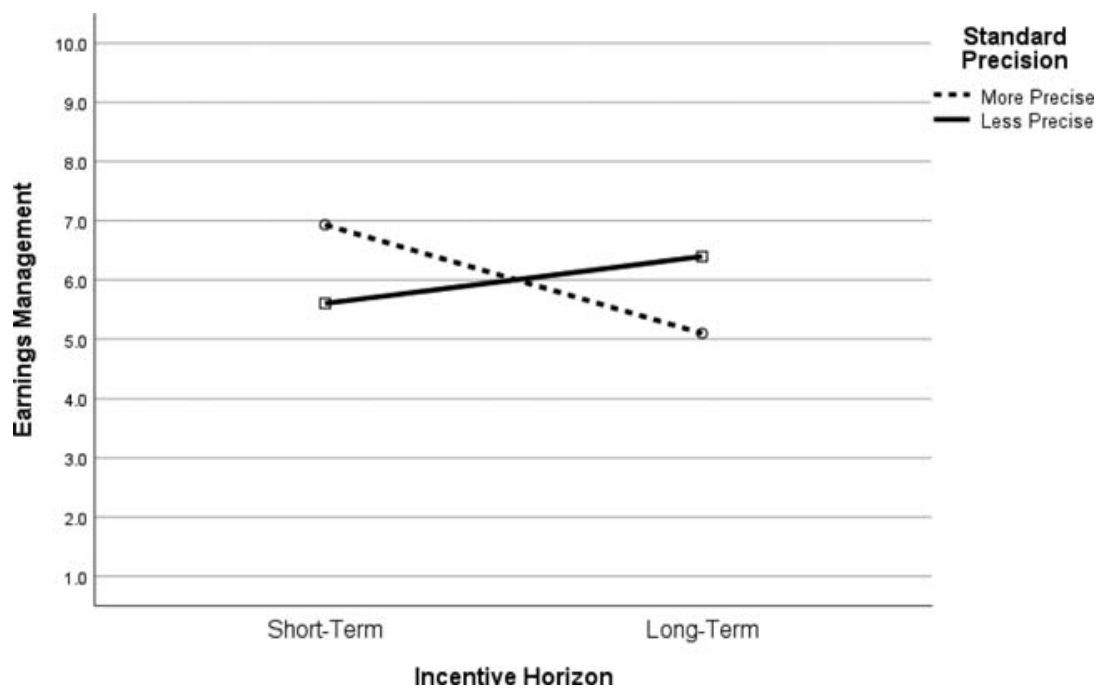

Figure 1. Effects of Standard Precision and Incentive Horizon on Income-Increasing Earnings Management. The Y-Axis represent EARNINGS_MANAGEMENT. Participants were asked to assess the likelihood that they would classify the lease as an operating lease or a capital lease on a ten-point scale where 1 represents less earnings management behaviour and 10 represents more earnings management behaviour.

providing further evidence that the decrease in capitalisation of the lease is more pronounced when standards are less precise, relative to more precise. ${ }^{15}$

\subsection{Mediation analyses}

The debriefing questions examine potential sources of influence on participants' lease classification decisions (see Table 2). Agoglia et al. (2011) find evidence that concerns about secondguessing by regulators and concerns about the economic substance of events mediate the relationship between standard precision and decisions to engage in aggressive financial reporting. We measure perceptions of concern for regulator second-guessing and economic substance in the debriefing questions and examine whether these act as mediating variables in our study. There is no evidence of any mediating effect of concerns about second-guessing by regulators in any experimental condition, and we, therefore, focus on concerns about economic substance.

Using the full sample and examining all treatment conditions, we do not find evidence that concerns about economic substance is a mediating variable. However, our main finding demonstrates that the effects of the incentive horizon change for preparers using less precise standards versus more precise standards. Thus, there may be mediating effects of economic substance that depend upon the type of standard. To examine whether economic substance is a mediating variable when standards are less precise, versus more precise, we split the sample on STANDARD_$P R E C I S I O N$ and then test for mediating effects of economic substance on the relationship between INCENTIVE_HORIZON and EARNINGS_MANAGEMENT.

We perform mediation analyses following the procedures described by Hayes and Preacher (2014) and Hayes (2018). The method involves Model 4 from Hayes (2018) and employs 95

\footnotetext{
${ }^{15}$ As supplemental analysis, we created a dichotomous variable to represent whether or not participants chose to classify the lease as operational (and thus engage in earnings management). We performed a binary logistic regression using the dichotomous measure as a dependent variable and STANDARD_PRECISION, INCENTIVE_HORIZON, and the interaction term as independent variables. The interaction term is again significant $(p=0.020$ ), which provides further support for our hypothesis.
} 


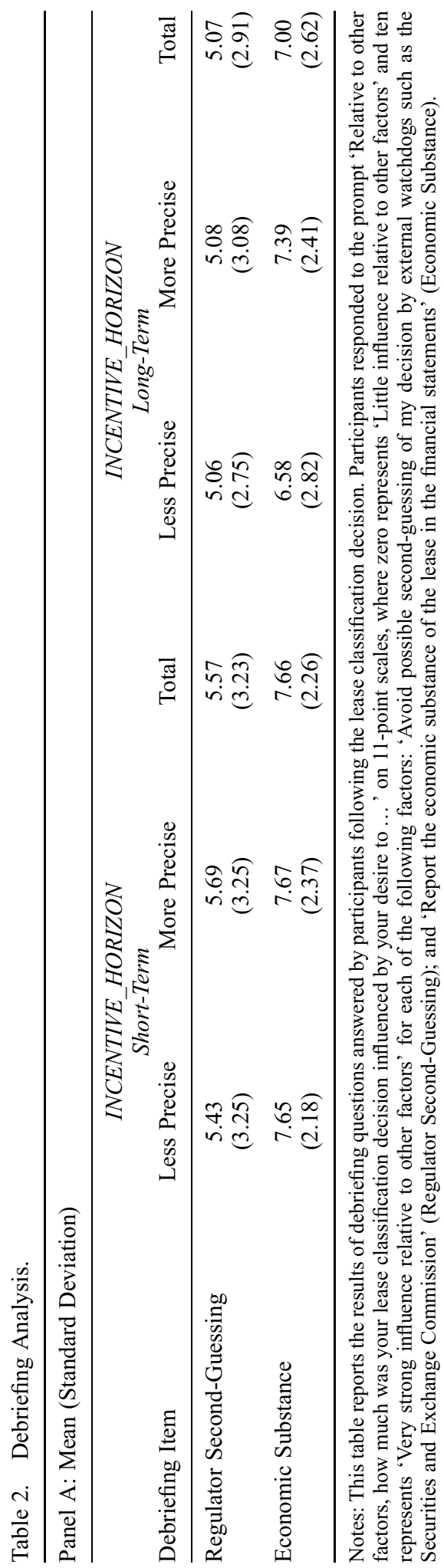




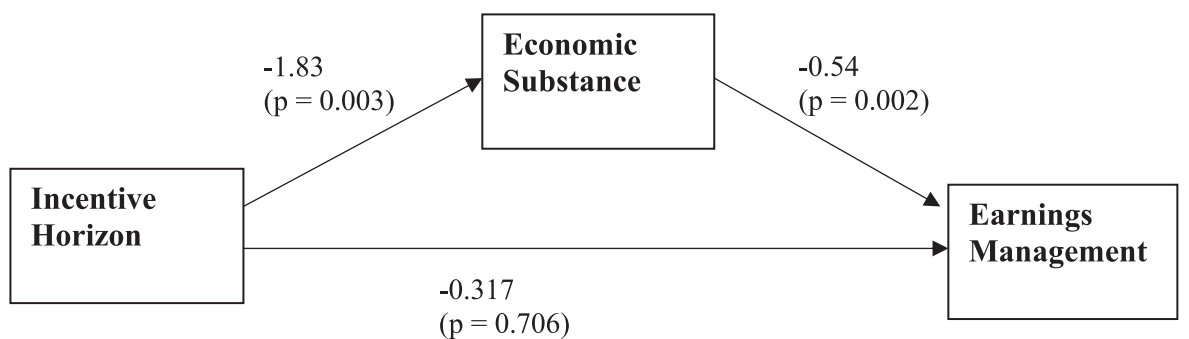

Figure 2. Mediation Effects of Economic Substance when Standards are Less Precise. INCENTIVE_HORIZON is an indicator variable where zero represents the short-term incentive condition, and one represents the long-term incentive condition. ECONOMIC_SUBSTANCE is measured with the following question and related scale. 'Relative to other factors, how much was your lease classification decision influenced by your desire to report the economic substance of the lease in the financial statements' on and 11point scale, where zero represents 'Little influence relative to other factors; and ten represents 'Very strong influence relative to other factors.' The dependent variable is EARNINGS_MANAGEMENT. Participants assess the likelihood that they would classify the lease as an operating lease or a capital lease on a tenpoint scale where 1 represents less income-increasing earnings management and 10 represents more income-increasing earnings management.

percent bias-corrected confidence intervals and 5,000 bootstrap samples. We first examine the low standard precision condition. Results of this mediation test indicate that concerns about the economic substance of the lease transaction mediates the relationship between INCENTIVE_HORIZON and EARNINGS_MANAGEMENT $(\mathrm{LLCI}=-1.955, \mathrm{ULCI}=-0.210)$. The mediation results are presented in Figure 2. The results suggest that when standards are less precise, controllers become less concerned about the economic substance of a transaction when the incentive horizon is longer. This is consistent with our expectations that preparers could place less emphasis on economic substance when their incentives do not involve maximising short-term profitability. This decrease in concern about economic substance translates into more earnings management. Employing the same mediation analysis techniques for the sample of preparers in the more precise standards condition reveals that concerns about the economic substance of the transaction is not a mediating variable when standards are more precise. Overall, we find that concerns about economic substance influence lease classification decisions, and this explains, at least partially, preparers' desire to take advantage of the flexibility inherent in less precise standards when the incentive horizon is long-term.

\subsection{Additional tests}

It is also important to explore whether these findings are a function of the standard precision manipulation creating different perceptions of the lease criteria. Specifically, for participants in the less precise standard precision condition, the term 'for the major part of' is open to their own interpretation, which might influence their lease classification. ${ }^{16}$ Following Agoglia et al. (2011), we examine whether the more and less precise

\footnotetext{
${ }^{16}$ It is possible that a participant in the less precise standard condition may interpret the phrase 'for the major part of' in a manner that creates a different decision context relative to the more precise treatment condition. Under both treatment conditions, participants must use professional judgment to determine whether the renewal option represents a bargain, and thus whether it should be included in the lease term for the purposes of determining the appropriate lease classification using the provided standard. Within the more precise condition, once the decision regarding the renewal option has been made, the bright-line threshold of 75 percent must be applied to arrive at the appropriate lease classification. Thus, participants who make
} 
lease classification standards created different perceptions of the meaning of 'for the major part,' by asking participants the following question:

If a criterion for classifying a lease as a capital lease is if the lease term is for the major part of the economic life of the asset, what is the minimum percentage you would assign to the expression 'for the major part of'

(Please answer on a scale of $0 \%$ to $100 \%$ ). $\%$

Participants in the less precise condition perceived that 'for the major part of' represented a lower percentage (mean $=62.62, p=0.038$ ) relative to participants in the precise treatment condition (mean $=68.49$ ). Therefore, we include this perception as a covariate and repeat the analyses above to test our hypothesis. Importantly, the results are unchanged by including this covariate. As an additional test, we follow Agoglia et al. (2011) and repeat our analyses using only the participants who indicated that their perception of 'for the major part of' fell within the range of 70 percent to 80 percent. Thus, this test directly compares participants who had similar perceptions of the lease criterion during the experiment. Of the 67 participants in the less precise standard treatment, 26 responded within the 70-80 percent range. We retest our hypothesis using only these participants. We find results similar to our initial results, and there is also a marginally significant interaction between STANDARD_PRECISION and INCENTIVE_HORIZON $(p<0.11)$ with the reduced sample.

Given that our sample comprises financial statement preparers from both the United States (61) and Bangladesh (86), we also examine whether there is a country effect on the ANOVA results. Participants from the United States have frequent exposure to precise, rules-based standards, which are considered prevalent in US GAAP. In contrast, Bangladesh follows the Bangladesh Financial Reporting Standards, which are closely modelled after International Accounting Standards and IFRS. The Bangladesh standards are considered more principles-based in nature and tend to be less precise than US GAAP. As a result, it is possible that our results may be influenced by preparers' familiarity with different standard types. To explore the potential for familiarity with different standards to influence our findings, we create an indicator variable for the country of origin of our participants $(0=$ US participant, $1=$ Bangladesh participant $)$ and include this covariate in the model used to test our hypothesis. The country indicator variable is not statistically significant $(\mathrm{F}=0.543, p=0.462)$, and results of hypothesis testing are unchanged. ${ }^{17}$ Our results are robust for financial preparers who are familiar with either more or less precise standards, which indicates that familiarity with certain types of standards is not a driver of the results.

the same judgment regarding whether the renewal option represents a bargain should reach the same lease classification decision. Within the less precise condition, a participant's interpretation of what constitutes 'for the major part of' the lease term will influence their ultimate classification. For example, a participant that interprets 'for the major part of' to mean 60 percent of the lease term will arrive at a different classification than a participant who interprets the phrase to mean 90 percent, given the same set of case facts. Accordingly, participants who make the same judgment regarding whether the renewal option represents a bargain may not necessarily arrive at the same lease classification decision.

${ }^{17} \mathrm{We}$ also analysed a model where we examined whether country of origin interacts with either standard precision or the incentive horizon. There are no interactive effects, which again supports the argument that results are robust for preparers from different standard regimes. Further, we included the country dummy in moderated mediation models to determine whether country influenced the mediating effects of economic substance on the lease classification decision. The country dummy was also not statistically significant in any of these models. 
Additionally, we examined whether there is an effect of job title (Chief Financial Officer vs. other managerial accounting and finance position) on our results. To explore whether there were classification differences between $\mathrm{CFO}$ and other managerial accounting and finance professionals, we create an indicator variable based on the participant's self-reported job title $(0=$ non-CFO, $1=\mathrm{CFO})$. There is no significant difference in lease classification between CFOs and non-CFOs $(\mathrm{F}=0.119, p=0.731)$, and including the indicator variable as a covariate does not influence the results of our hypotheses testing.

\section{Summary and conclusions}

Prior literature tends to support a less rules-based approach to standard setting, as it finds that less precise standards are more effective at reducing income-increasing earnings management behaviour relative to more precise, rules-based standards. Our study examines whether these findings hold in decision contexts that have not previously been considered. Specifically, we examine how standard precision and the incentive horizon of financial statement preparers jointly influence the reporting decisions of financial statement preparers. Given the increased use of incentive structures that emphasise long-term performance (such as share-based compensation with restrictions and holding requirements) (Lovett et al. 2021), it is important to explore how this impacts the relationship between standard precision and earnings management behaviour.

Consistent with expectations, we find that the incentive horizon of executives in a firm changes the nature of earnings management decisions made by financial statement preparers. When the incentive horizon changes from short-term to long-term, income-increasing earnings management behaviour increases more when standards are less precise, relative to more precise. Mediation analyses reveal that these results are partially explained by differences in concerns about the economic substance of transactions when the incentive horizon is short-term versus long-term.

Taken together, our findings challenge some key conclusions from the existing literature. While much of the support for the adoption of principles-based standards comes from the belief that principles-based standards reduce earnings management relative to more rulesbased standards (Nelson et al. 2002, Maines 2007, Agoglia et al. 2011, Dichev et al. 2013), we provide evidence that more precise, rules-based standards can also limit earnings management behaviour. The use of compensation plans that include long-term incentives such as stock holding requirements has grown substantially in recent years due to their capacity to increase managers' focus on their firms' long-term goals, and these forms of compensation may change the landscape with regards to the effects of standard precision on earnings management behaviour. As compensation plans continue to evolve, our findings indicate that the profession cannot assume that less precise, principles-based standards consistently reduce earnings management and other opportunistic behaviours more than precise, rules-based standards. Thus, there appear to be opportunities to take advantage of more precise rules to create a common knowledge base and common assumptions for financial reporting (Schipper 2003, Shortridge and Myring 2004) without the threat of more earnings management behaviour.

Future research could extend our line of inquiry by examining standard precision in alternate settings to identify other factors that may moderate the relationship between standard precision and aggressive financial reporting. Two potential limitations of our study are our decision context and our measurement of earnings management. Our case focuses on the context of lease classification because we extend prior research related to lease standards. However, this standard has been revised by the FASB and IASB. Thus, to broaden the generalizability of our findings, future research could examine standard precision using alternative standards. In addition, we measure earnings management with the decision to capitalise or expense a lease. There are many other 
ways to measure earnings management behaviour. For example, the use of measures that include the amount of earnings management that practitioners are willing to engage in would provide further insights. Future research could also enhance our understanding of the role that standard precision plays in influencing financial statement preparers' decisions to engage in earnings management behaviour.

Overall, we provide evidence that incentive structures and the precision of accounting standards work together to influence the choice to engage in income-increasing financial reporting. The results reveal that our understanding of the effects of standard precision on financial preparers' decisions is incomplete without simultaneously considering the influence of incentive structures, and the findings have important implications for both research and practice. The results suggest that migration to principles-based standards may not result in the expected reductions in earnings management behaviour. In fact, in the current environment where incentive systems often include stock-based compensation with long holding requirements, the possible movement towards principles-based standards could actually result in an increase in earnings management activities.

\section{Acknowledgement}

We thank Ali Abdolmohammadi, Chris Agoglia, Jean Bedard, participants of workshops at Bentley University, University of Rhode Island and Fairfield University for their helpful comments. We also wish to thank the experienced professionals who gave their time to participate in this research.

\section{Disclosure statement}

No potential conflict of interest was reported by the author(s).

\section{References}

Agoglia, C. P., Doupnik, T.S., and Tsakumis, G.T., 2011. Principles-based versus rules-based accounting standards: The influence of standard precision and audit committee strength on financial reporting decisions. The Accounting Review, 86 (3), 747-767.

Alexander, A, 1999. A benchmark for the adequacy of published financial statements. Accounting and Business Research, 29 (Summer), 239-253.

American Accounting Association Financial Accounting Standards Committee, 2003. Evaluating conceptsbased vs. rules-based approaches to standard setting. Accounting Horizons, 17 (1), 73-89.

American Institute of Certified Public Accountants (AICPA), 2002. Consideration of Fraud in a Financial Statement Audit. Statement on Auditing Standards No. 99. New York, NY: AICPA.

Antia, M., Pantzalis, C., and Park, J.C., 2010. CEO incentive horizon and firm performance: An empirical investigation. Journal of Corporate Finance, 16 (3), 288-301.

Balkin, D. B., and Gomez-Mejia, L. R., 1990. Matching compensation and organizational strategies. Strategic Management Journal, 11 (2), 153-169.

Ball, R, 2016. IFRS - 10 years later. Accounting and Business Research, 46 (5), 545-571.

Barth, M. E., Elliott, J. A., and Finn, M. W., 1999. Market rewards associated with patterns of increasing earnings. Journal of Accounting Research, 37 (Autumn), 387-413.

Bebchuk, L., and Fried, J., 2003. Executive compensation as an agency problem. Journal of Economic Perspectives, 17, 71-92.

Bebchuk, L., and Fried, J., 2010. Paying for long-term performance. University of Pennsylvania Law Review, 158 (7), 1915-1959.

Bergstresser, D., and Philippon, T., 2006. CEO incentives and earnings management. Journal of Financial Economics, 80 (3), 511-529.

Brink, A., Gouldman, A., Rose, J., and Rotaru, K., 2020. Effects of executive compensation structure and R\&D reporting method on psychophysiological responses and real earnings management decisions of subordinate managers. Management Accounting Research, 48.

Chava, S., and Purnanandam, A, 2010. CEOs versus CFOs: incentives and corporate policies. Journal of Financial Economics, 97 (2), 263-278. 
Cheng, Q., and Warfield, T.D., 2005. Equity incentives and earnings management. The Accounting Review, 80 (2), 441-476.

Dechow, P., and Sloan, R., 1991. Executive incentives and the horizon problem: an empirical investigation. Journal of Accounting and Economics, 14 (1), 51-89.

Defond, M. L., and Jiambalvo, J., 1993. Factors related to methods. Contemporary Accounting Research, 9, 415-431.

Dichev, I. D., Graham, J. R., Harvey, C. R., and Rajgopal, S., 2013. Earnings quality: evidence from the field. Journal of Accounting and Economics, 56, 1-33.

Folsom, D., Hribar, P., Mergenthaler, R., and Peterson, K., 2016. Principles-based standards and earnings attributes. Management Science, 63, 2592-2615.

Francis, J. R., and Krishnan, J., 1999. Accounting accruals and auditor reporting conservatism. Contemporary Accounting Research, 16, 135-165.

Gigler, F., Kanodia, C., Sapra, H., and Venugopalan, R, 2014. How frequent financial reporting can cause managerial short-termism: An analysis of the costs and benefits of increasing reporting frequency. Journal of Accounting Research, 52 (2), 357-387.

Gopalan, R., Milbourn, T., Song, F., and Thakor, A. V., 2014. Duration of executive compensation. The Journal of Finance, 69 (6), 2777-2817.

Graham, J. R., Harvey, C. R., and Rajgopal, S., 2005. The economic implications of corporate financial reporting. Journal of Accounting and Economics, 4, 3-73.

Hayes, A. F., and Preacher, K. J., 2014. Statistical mediation analysis with a multicategorical independent variable. British Journal of Mathematical and Statistical Psychology, 67 (3), 451-470.

Hayes, A. F, 2018. Introduction to Mediation, Moderation, and Conditional Process Analysis. New York: Guilford Press.

Hershfield, H. E., Cohen, T.R., and Thompson, L., 2012. Short horizons and tempting situations: lack of continuity to our future selves leads to unethical decision making and behavior. Organizational Behavior and Human Decision Processes, 117 (2), 298-310.

Imhoff, E., and Thomas, J., 1988. Economic consequences of accounting standards: the lease disclosure rule change. Journal of Accounting and Economics, 10 (4), 277-310.

International Federation of Accountants (IFAC), 2009. International Standard on Auditing (ISA) 240: The Auditor's Responsibilities Relating to Fraud in an Audit of Financial Statements. New York: IFAC. http://web.ifac.org/download/ISA_240_standalone_2009_Handbook.pdf.

Jastrow, J, 1899. The mind's eye. Popular Science Monthly, 54, 299-312.

Jastrow, J, 1900. Fact and Fable in Psychology. Boston: Houghton Mifflin.

Jensen, M.C., and Meckling, W.H., 1976. Theory of the firm: managerial behavior, agency costs and ownership structure. Journal of Financial Economics, 3 (4), 305-360.

Johnson, S. A., Ryan, H. E., and Tian, Y. S., 2009. Managerial incentives and corporate fraud: The sources of incentives matter. Review of Finance, 13 (1), 115-145.

Kulas, J. T., Stachowski, A. A., and Haynes, B. A., 2008. Middle response functioning in Likert-responses to personality items. Journal of Business and Psychology, 22 (3), 251-259. doi: 10.1007/s10869-0089064-2.

Leuz, C, 2010. Different approaches to corporate reporting regulation: how jurisdictions differ and why. Accounting and Business Research, 40 (3), 229-256.

Lovett, S., Rasheet, A. A., and Hou, W., 2021. Stock options, restricted stock, salary or bonus? Managing CEO compensation to maximize organizational performance. Business Horizons. doi:10.1016/j.bushor. 2021.02.041.

Maines, L, 2007. Spotlight on principles-based financial reporting. Business Horizons, 50 (5), 359-364.

Marginson, D., and McAulay, L., 2008. Exploring the debate on short-termism: a theoretical and empirical analysis. Strategic Management Journal, 29 (3), 273-292.

McCarthy, M., and McCarthy, R., 2014. Financial statement preparers' Revenue decisions: accuracy in applying rules-based standards and the IASB-FASB Revenue recognition model. Journal of Accounting and Finance, 14 (6), 21-43.

Morck, R., Shleifer, A., and Vishny, R. W., 1988. Management ownership and market valuation: An empirical analysis. Journal of Financial Economics, 20, 293-315.

Narayanan, M.P, 1996. Form of compensation and managerial incentive horizon. Journal of Financial and Quantitative Analysis, 31 (4), 467-491.

Nelson, M. W., Elliott, J. A., and Tarpley, R. L., 2002. Evidence from auditors about managers' and auditors' earnings management decisions. The Accounting Review, 77, 175-202. 
Nelson, M. W, 2003. Behavioral evidence on the effects of principles- and rules-based standards. Accounting Horizons, 17 (1), 91-104.

Nobes, C. W, 2005. Rules-based standards and the lack of principles in accounting. Accounting Horizons, 19 (1), 25-34.

Nobes, C, 2006. The survival of international differences under IFRS: towards a research agenda. Accounting and Business Research, 36 (3), 233-245.

Peytcheva, M., 2021. Duck or Rabbit? Joint Effects of Accounting Standard and Transaction Ambiguity on Aggressive Reporting by Managers in the Presence of Incentives to Report Aggressively. Working Paper, LeHigh University.

Psaros, J., and Trotman, K. T., 2004. The impact of the type of accounting standards on preparers' judgments. Abacus, 40 (1), 76-93.

Raaijmakers, Q. A., Hoof, A. V., Hart, H. T., Verbogt, T. F., and Wollebergh, A. M., 2000. Adolescents' midpoint response on Likert-type scale items: neutral or missing values? International Journal of Public Opinion Research, 12 (2), 208-216.

Schipper, K, 2003. Principles-based accounting standards. Accounting Horizons, 17 (1), 61-72.

Schipper, K, 2005. The introduction of international accounting standards in Europe: implications for international convergence. European Accounting Review, 14 (1), 101-126.

Schuler, R. S., and MacMillan, I. C., 1984. Gaining competitive advantage through human resource management practices. Human Resource Management, 23, 241-255.

Schreiber, S. P, 2014. Notice defines terms for economic substance doctrine. Journal of Accountancy. Available from: https://www.journalofaccountancy.com/news/2014/oct/201411106.html\#: :text=7701 (o) $\% 2 \mathrm{C} \% 20$ which $\% 20$ defines, for $\% 20$ entering $\% 20$ into $\% 20$ the $\% 20$ transaction.

Shortridge, R. T., and Myring, M., 2004. Defining principles-based accounting standards. The CPA Journal, $74(8), 34-37$.

Worcester, R. M., and Burns, T. R., 1975. A statistical examination of the relative precision of verbal scales. Journal of the Market Research Society, 17 (3), 181-197.

Wüstemann, J., and Wüstemann, S., 2010. Why consistency of accounting standards matters: a contribution to the rules-versus-principles debate in financial reporting. Abacus, 46 (1), 1-27. 